Check for updates

Cite this: RSC Adv., 2017, 7, 51729

Received 1st August 2017

Accepted 30th October 2017

DOI: $10.1039 / c 7 r a 08483 h$

rsc.li/rsc-advances

\section{In vitro antimicrobial and in vivo wound healing effect of actinobacterially synthesised nanoparticles of silver, gold and their alloy $\dagger$}

\author{
Thangavel Shanmugasundaram, (D) ab Manikkam Radhakrishnan, (D) ${ }^{c}$ \\ Venugopal Gopikrishnan, (D) Krishna Kadirvelu (D) ${ }^{\text {b }}$ \\ and Ramasamy Balagurunathan (DD*a
}

\begin{abstract}
The therapeutic use of metal and alloy nanoparticles is claimed to have reduced side effects and enhanced curative activity as compared to its ionic counterpart. With this view, the present study focused on the synthesis of silver ( $\mathrm{Ag}$ ), gold ( $\mathrm{Au}$ ) and silver/gold ( $\mathrm{Ag} / \mathrm{Au}$ ) nanoparticles (NPs) by using actinobacterial metabolites as a reducing agent for enhanced in vitro antimicrobial and in vivo wound healing activities. Physico-chemical parameters of the synthesised nanoparticles were systematically assessed by using Xray based spectroscopic, zeta potential, dynamic light scattering (DLS), atomic and electron microscopic analysis. The average sizes of the AgNPs, AuNPs and Ag/AuNPs were found to be $30.5 \mathrm{~nm}, 14.5 \mathrm{~nm}$ and $41.5 \mathrm{~nm}$ respectively. The synthesized AgNPs and Ag/AuNPs showed better antibacterial activity on Gram negative bacterial pathogens (Escherichia coli, Pseudomonas aeruginosa and Aeromonas hydrophila) than Gram positive bacterial pathogens. A Minimum Inhibitory Concentration (MIC) value of $6.25 \mu \mathrm{g} \mathrm{ml}^{-1}$ was observed for E. coli, P. aeruginosa and Candida albicans. AgNP and Ag/AuNP based ointments of about $10 \%$ concentration heal (100\%) the excision wound within 19 and 21 days in contrast with standard ointment. Further, the complete healing process was evaluated by histopathological analysis, and estimation of tensile strength, inflammatory cytokines (IL-6, TNF $\alpha, I L-10)$ and collagen constituents (hexosamine, hydroxyproline and hyaluronic acid). Metal and alloy nanoparticle use may provide a new and effective therapeutic direction for achieving development of novel antimicrobial drugs and scarless wound healing in clinical practice.
\end{abstract}

\section{Introduction}

Infection control is exclusively important within healthcare settings, where the risk of infection to patients is critically increased. Regarding the epidemiological evolution, infectious diseases remain a public health problem; they are a significant cause of morbidity and mortality worldwide, especially in developing countries. Infectious diseases are an insistent global problem, costing lives, reducing life expectancy, weakening economic growth and increasing the pressure on health systems. ${ }^{1}$ In 2013, the global mortality related to infection in the human population was 11.8 million. In fact, the developments made in preventive actions such as hygiene practices,

${ }^{a}$ Actinobacterial Research Laboratory, Department of Microbiology, Periyar University, Periyar Palkalai Nagar, Salem 636 011, Tamil Nadu, India. E-mail: actinobalaguru@ gmail.com; Fax: +91-427-2345124; Tel: +91-427-2345766 ext. 227

${ }^{b} D R D O-B U$ Centre for Life Sciences, Bharathiar University Campus, Coimbatore 641 046, Tamil Nadu, India

${ }^{c}$ Centre for Drug Discovery and Development, Sathyabama University, Jeppiaar Nagar, Chennai 600 119, Tamil Nadu, India

$\dagger$ Electronic supplementary information (ESI) available. See DOI: $10.1039 / \mathrm{c} 7 \mathrm{ra} 08483 \mathrm{~h}$ vaccination, and antibiotic therapy have been countered by the continuing emergence and re-emergence of infectious diseases and microbial resistance to antibiotics. ${ }^{2-4}$ Consumption of antimicrobial drugs has increased by nearly $40 \%$ in the last decade worldwide. ${ }^{5}$ Infectious diseases cost the worldwide economy billions of dollars annually, ${ }^{6}$ by the requirement for long-term hospitalization and healthcare. ${ }^{7,8}$ In India, the range and burden of infectious diseases is enormous and it contributes to about $30 \%$ of total disease burden. ${ }^{9}$

Particularly the threat of Gram-negative bacteria, such as Acinetobacter, Pseudomonas and various Enterobacteriaceae (including Klebsiella, E. coli, Serratia, and Proteus) that are resistant to most of the antibiotics, including carbapenems and third generation cephalosporins - the best available antibiotics for treating multi-drug resistant bacterial pathogens. ${ }^{10}$ Additionally, they are the prime agents of severe and often deadly infections such as bloodstream infections and pneumonia. There is a broad increase in the number of antibiotic resistance in medically important pathogenic and opportunistic microorganisms obliges the scientific community to continuously develop new drugs and drug targets. New antimicrobial agents have been developed in the last decade due to the continuous 
selection of antibiotic resistance traits and none of them has enhanced the activity against multidrug-resistant bacteria and other pathogens. Additionally, nanoparticles have demonstrated their antimicrobial activities, the development of novel applications in this field makes them an attractive alternative to commercial antibiotics. ${ }^{11}$ Similarly, emerging antiviral drugs targeting the virus and maintaining host cell viability is a challenging one, causing millions of circumstances every year. ${ }^{\mathbf{1 2 , 1 3}}$ For instance, nanoparticles have been examined for their ability to reduce infections in skin $^{14}$ and burn wounds. ${ }^{15}$ Wound healing is a natural curative response to tissue injury and is able by a complex cascade of biochemical and cellular reactions that generate resurfacing, restoration and reconstitution of the tensile strength of the injured skin. ${ }^{16}$ The ultimate goal for wound healing is an immediate recovery with minimal scarring and maximal function. ${ }^{17}$ Normally healing process includes four phases such as, hemostasis, inflammation, proliferation and maturation which typically lead to scar formation. ${ }^{\mathbf{1 8}}$

Applications of metallic nanoparticles in the biomedical fields are abundant, and there is a strong potential for continued growth in this area. Over the past few decades, inorganic nanomaterials, whose structures reveal significantly novel with improved physico-chemical, biological properties and functionality due to their nanometre size, have encouraged much interest. Since nanoparticles are more biocompatible than the conventional therapeutic carriers, they are exploited for drug encapsulation and delivery. ${ }^{19}$ It has been stressed over the years that size reduction of nanomaterial plays a significant role in improving their bioavailability for therapeutic applications in disease diagnosis like cancer, AIDS, etc. ${ }^{20}$ Based on this view, the present study focused on the enhanced antimicrobial and wound healing activities of actinobacterially synthesised $\mathrm{Ag}, \mathrm{Au}$ and $\mathrm{Ag} / \mathrm{Au}$ alloy nanoparticles.

\section{Materials \& methods}

\section{Description of nanoparticles and their characterization}

In this study, the nanoparticles such as AgNPs, AuNPs and Ag/ AuNPs were synthesised by an extremophilic actinobacterium, Streptomyces sp. B5 using bio-reduction process. The detailed biosynthesis process and characterization of the nanoparticles using, UV-vis spectroscopy, FT-IR, XRD, XPS, HR-TEM with SAED pattern was reported. ${ }^{21}$ In addition, Scanning Electron Microscopic (SEM) analysis was done by using FE - SEM (Model ZWISS, Germany). A thin film was prepared by using the sample containing metal and its alloy nanoparticles, on a carbon coated copper grid by just dropping a very small amount of the sample on the grid. The extra sample was removed using a blotting paper and then the film on the SEM grid was allowed to dry by putting it under a mercury lamp for $5 \mathrm{~min}$. After that, the film was magnified at different resolution power for the observation of nanoparticles. In order to perform AFM analysis, the nanoparticles were mixed with methanol and a drop of mixture deposited on a silicon slide and allowed to solvent evaporation. Then, the thin film $(1 \mathrm{~cm} \times 1 \mathrm{~cm})$ containing the sample was analyzed using AFM (Model Nanosurf A). Energy Dispersive Xray (EDX) measurements of the nanoparticles were carried out by SEM-EDX (Model ZWISS, Germany). The sample was prepared by casting the biosynthesized nanoparticles on a carbon-coated copper grid and placed for analysis. In the analysis, the presence of nanoparticles is confirmed by strong elemental $\mathrm{Ag}$ and Au signals.

Dynamic light scattering (DLS) was carried out to determine the size distribution of the nanoparticles. Zeta Potential was used to determine the surface charge of nanoparticles in colloidal solutions as well as colloidal solution stability. It was carried out in Zetasizer Nano-2S (Malvern Instruments Ltd, UK) ranging from $+100 \mathrm{mV}$ to $-100 \mathrm{mV}$.

\section{Antimicrobial activity}

Antibacterial activity by agar well diffusion assay. Human bacterial pathogens such as, Staphylococcus aureus (NCIM 2079), Bacillus subtilis (NCIM 2063), Klebsiella pneumoniae (NCIM 2706), Escherichia coli (NCIM 2256), Pseudomonas aeruginosa (NCIM 5031), Serratia marcescens (NCIM 5246) and fish pathogens such as, Aeromonas hydrophila (NCIM 5286), Providencia vermicola (MTCC 5578) were procured from Actinobacterial Research Laboratory, Periyar University, Salem.

Metals $(\mathrm{Ag}, \mathrm{Au})$ and their alloy $(\mathrm{Ag} / \mathrm{Au})$ nanoparticles were tested against bacterial strains by using well diffusion method. ${ }^{22}$ Pure cultures were subcultured in Muller Hinton (MH) broth for $24 \mathrm{~h}$ at $37^{\circ} \mathrm{C}$. Each strain was swabbed uniformly onto the individual Muller Hinton agar (MHA) plates using sterile cotton swabs and wells of $5 \mathrm{~mm}$ diameter were made using well puncture. Using sterile micropipette, the $\mathrm{Ag}, \mathrm{Au}, \mathrm{Ag} / \mathrm{Au}$ nanoparticles and their corresponding metal salt solutions (silver nitrate and gold chloride) $\left(50 \mu \mathrm{l}, 1 \mathrm{mg} \mathrm{ml}^{-1}\right.$ concentration) were poured into each of the wells in all the plates. For the comparative study, the standard AgNPs ( $35 \mathrm{~nm})$, AuNPs $(\sim 20 \mathrm{~nm})$ and $\mathrm{Ag} / \mathrm{AuNPs}(\sim 50 \mathrm{~nm})$ also was poured into the wells at the same concentrations. The plates were then incubated for $24 \mathrm{~h}$ at $37^{\circ} \mathrm{C}$ and the zone of inhibition was measured and the morphologically induced changes in control and AgNPs, Ag/AuNPs treated bacterial (Escherichia coli and Pseudomonas aeruginosa) cells were analyzed by field emission scanning electron microscopy (FE-SEM) with energy dispersive X-ray (EDX) pattern (ZWISS, Germany).

Antifungal activity by agar well diffusion assay. Biosynthesised nanoparticles ( $\mathrm{Ag}, \mathrm{Au}$ and $\mathrm{Ag} / \mathrm{Au}$ ) were tested against fungal strains such as Candida albicans and Candida glabrata by using well diffusion method..$^{2324}$ Both the strains were obtained from Actinobacterial Research Laboratory, Periyar University, Salem. Pure cultures were subcultured in $\mathrm{MH}$ broth for $24 \mathrm{~h}$ at $37^{\circ} \mathrm{C}$. Each strain was swabbed uniformly onto the individual MHA plates using sterile cotton swabs and wells of $5 \mathrm{~mm}$ diameter were made using well puncture. Using sterile micropipette, the biosynthesised nanoparticles, corresponding metal salt solutions and standard nanoparticles $(50 \mu \mathrm{l}$, $2 \mathrm{mg} \mathrm{ml}^{-1}$ concentration) were poured into each of the wells in all the plates. Then the plates were incubated at $37{ }^{\circ} \mathrm{C}$ for 24-48 $\mathrm{h}$ and the zone of inhibition was measured.

Minimum inhibitory concentration (MIC) and minimum bactericidal concentration (MBC) studies. The antimicrobial 
efficacy of biosynthesized nanoparticles was studied by using standard broth dilution method. ${ }^{25}$ The MIC was determined in Muller Hinton broth using serial two-fold dilutions of nanoparticles in concentrations ranging from $1.5625 \mu \mathrm{g} \mathrm{ml} \mathrm{m}^{-1}$ to $100 \mu \mathrm{g} \mathrm{ml}^{-1}$ with adjusted microbial concentrations (OD: 0.10 at $625 \mathrm{~nm}, 0.5$ McFarland's standard, $1 \times 10^{8} \mathrm{CFU} \mathrm{ml}^{-1}$ ) in sterile 96 well plates. The positive control used in this study contained $\mathrm{MH}$ broth medium with tested bacterial [Staphylococcus aureus (NCIM 2079), Escherichia coli (NCIM 2256), Klebsiella pneumoniae (NCIM 2706), Pseudomonas aeruginosa (NCIM 5031), Serratia marcescens (NCIM 5246)] and fungal [Candida albicans] concentrations and negative control was uninoculated broth. The plates were incubated at $37^{\circ} \mathrm{C}$ for $24 \mathrm{~h}$, respectively. The MIC is the lowest concentration of antimicrobial agents that visually inhibits 99\% growth of tested bacterial and fungal strains. The MIC was noted by the visual turbidity of the tubes both before and after incubation and it was done in three sets to confirm its value for the tested pathogens.

After the MIC determination of the biosynthesised nanoparticles, aliquots of $100 \mu \mathrm{l}$ from all the wells, which showed no visible bacterial growth was seeded in $\mathrm{MH}$ agar plates (not supplemented with any nanoparticles) and were incubated at $37^{\circ} \mathrm{C}$ for $24 \mathrm{~h}$. The MBC was noted for the presence or absence of microbial growth in agar plates before and after incubation. The MBC endpoint is calculated as the lowest concentration of antimicrobial agent that kills $99.9 \%$ of the initial bacterial population.

\section{Wound healing activity (excision wound model)}

Preparation of ointment. About $4.50 \mathrm{~g}$ of petroleum jelly was added with $0.5 \mathrm{~g}$ of the nanoparticle samples and stirred to produce $10 \%$ nanoparticle formulated ointments. These ointments were used for topical applications. ${ }^{26}$

Animals. Wistar albino rats (animal code: 003) of both sex, weight ranging from 100-150 g prevailed from $\mathrm{KMCH}$ College of Pharmacy, Coimbatore, India. Experimental protocols and procedures followed in the study were approved by institutional animal ethical committee (IAEC/KMCRET/Ph.D/10/ 2015-16) as per the guidance of committee for the purpose of Control and Supervision of Experiments on Animals (CPCSEA), Ministry of Environment and Forest, Government of India. The rats were maintained in a laboratory propylene cage under standard environmental conditions with regular diet and water ad libitum. For this study, all the experimental protocols and procedures were used by following the standard guidelines that were approved by the institutional animal ethical committee. A day prior to the wound healing experiments all the rats' dorsal sides were shaved. Anesthetic ether was used for anesthesia and $50 \mathrm{~mm}^{2}$ predetermined area on the backside were excised using a sterile crucial blade. Each group consist three animals. The experimental group specifications are as follows;

Group I: Control animals (Only wound)

Group II: Wound + Standard ointment (Nitrofurazone, $0.2 \% \mathrm{w} / \mathrm{w}$ )

Group III: Wound + 10\% Ointment base with AgNPs
Group IV: Wound + 10\% Ointment base with AuNPs

Group V: Wound $+10 \%$ Ointment base with Ag/AuNPs

Experiments. The ointments were applied regularly on the excised region and the wound area was covered with dressings in consequent days. The wound size reductions in length and breadth were measured regularly and changes in the wound sizes were photographed. The wound healing percentage was calculated by using the formula, Percentage of wound contraction $=$ HA/TA $x 100$ (where, HA - healed area, TA - total area, healed area $=$ original wound area - present wound area) was recorded till the complete healing of the excision wound.

Histopathological analysis. In the histopathological analysis, the damaged skins of the control and treated animals $\left(5^{\text {th }}\right.$ and $21^{\text {st }}$ day) were removed and immersed in a fixative solution containing $4 \%$ of phosphate - buffered paraformaldehyde for $24 \mathrm{~h}$ at room temperature. The specimens were then washed under running tap water and processed for histopathological embedding in paraffin. Longitudinal sections $(5 \mu \mathrm{m})$ were consecutively cut with a manual microtome and stained with hematoxylin-eosin (HE) for histological observations. The sections were examined under light microscopy at $400 \times$ magnifications.

Mechanical wound strength testing. The tissue breaking strength tests were carried out in tension on Dak system Inc's U.T.M. testing machine with computerized data capture and a maximum loading capacity of $500 \mathrm{~kg}$ at SITRA, Coimbatore. A $500 \mathrm{~kg}$ load cell with pneumatic grip was used. The transverse gripping load on the specimen was about $200 \mathrm{~kg}$, which minimized the grip damage. The ultimate breaking strength of the specimens (tissue samples) was taken as the maximum tensile test force $\left(100 \mathrm{~mm} \mathrm{~min}^{-1}\right)$ at final rupture. Results from specimens displaying failure initiated at the grips or at a flaw other than one associated with the anastomosis were not accepted for analysis. ${ }^{27}$

Estimation of pro-inflammatory and anti-inflammatory cytokine induction. Blood samples were collected from all animals of each group on days 0 and 21 after wounding. Estimation of pro-inflammatory (TNF $\alpha$ and IL-6) and antiinflammatory cytokines (IL-10) levels were done by performing enzyme linked immunosorbent assays (ELISAs) using commercial kits. ELISA kits for the determination of TNF $\alpha$ (Cat. No. EH3TNFA), IL-6 (Cat. No. EH2IL6), and IL-10 (Cat. No. EHIL10) were obtained from Thermo Fisher Scientific, USA. Assays were performed according to the manufacturer's instructions. The cytokine concentrations were calculated in

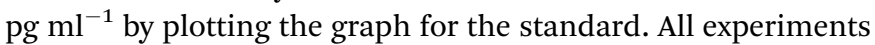
were done in triplicate to confirm the accuracy of the observations.

Estimation of hydroxyproline, hexosamine and hyaluronic acid. After the $5^{\text {th }}$ and $21^{\text {st }}$ days of wounding, pieces of skin from the healed wound area were collected and examined for their levels of hydroxyproline, which is the basic constituent of collagen. Collected tissues were dried in a hot air oven at 60$70{ }^{\circ} \mathrm{C}$ to an equal weight and hydrolyzed in $6 \mathrm{~N} \mathrm{HCl}$ at $130{ }^{\circ} \mathrm{C}$ for $4 \mathrm{~h}$ in sealed tubes. The hydrolysate was neutralized to $\mathrm{pH} 7.0$ with $0.1 \mathrm{~N} \mathrm{KOH}$ and subjected to chloramine-T oxidation for $20 \mathrm{~min}$. The reaction was terminated by the addition of $0.4 \mathrm{M}$ 
perchloric acid and colour was developed with the help of Ehrlich reagent at $60{ }^{\circ} \mathrm{C}$ and measured at $557 \mathrm{~nm}$ using a UV-Vis spectrophotometer. $^{28}$ To estimate the hexosamine levels, the weighed granulation tissues were hydrolyzed in $6 \mathrm{~N} \mathrm{HCl}$ for $8 \mathrm{~h}$ at $98{ }^{\circ} \mathrm{C}$, neutralized to $\mathrm{pH} 7$ with $4 \mathrm{~N} \mathrm{NaOH}$, and diluted with Milli-Q water. The hexosamine content of granulation tissues was estimated as described protocols with minor modifications. ${ }^{29}$ The diluted solution was mixed with acetylacetone solution and heated to $96{ }^{\circ} \mathrm{C}$ for $40 \mathrm{~min}$. The mixture was cooled, and $96 \%$ ethanol was added, followed by the addition of an 4-dimethylamino-benzaldehyde solution (Ehrlich's reagent). The solution was thoroughly mixed and kept at room temperature for $1 \mathrm{~h}$, and the absorbance was measured at $530 \mathrm{~nm}$ using a double-beam UV-Vis spectrophotometer. The amount of hexosamine was determined by comparisons with a standard curve. For the estimation of hyaluronic acid, tissues were fixed with $5 \mathrm{ml}$ of sulfuric acid reagent and cooled to $4{ }^{\circ} \mathrm{C}$. The tubes are then heated for $10 \mathrm{~min}$ in a vigorously boiling distilled water bath and cooled to room temperature. (For extreme accuracy it is suggested that the tubes are to be cooled to $-70{ }^{\circ} \mathrm{C}$ before the sample is layered and then allowed to warm up to room temperature while being shaken). Then $0.2 \mathrm{ml}$ of carbazole reagent was added and the tubes are shaken again, heated in the boiling bath for a further $15 \mathrm{~min}$, and cooled to room temperature. The optical density (OD) is then read at $530 \mathrm{~nm}$ using a UV-Vis spectrophotometer. ${ }^{30}$ Glucuronolactone is used as the standard for estimation.

Statistical analysis. Values are expressed as means \pm SEM. Differences were evaluated by Student's $t$-test and $P$ values, less than 0.05 were considered as significant.

\section{Results \& discussion}

\section{Characterization of nanoparticles}

Due to the development of new antimicrobial agents and their production on a large scale in the last century, which was marked by major advances in the treatment of infectious diseases. ${ }^{31}$ However, the extensive use of antimicrobial agents
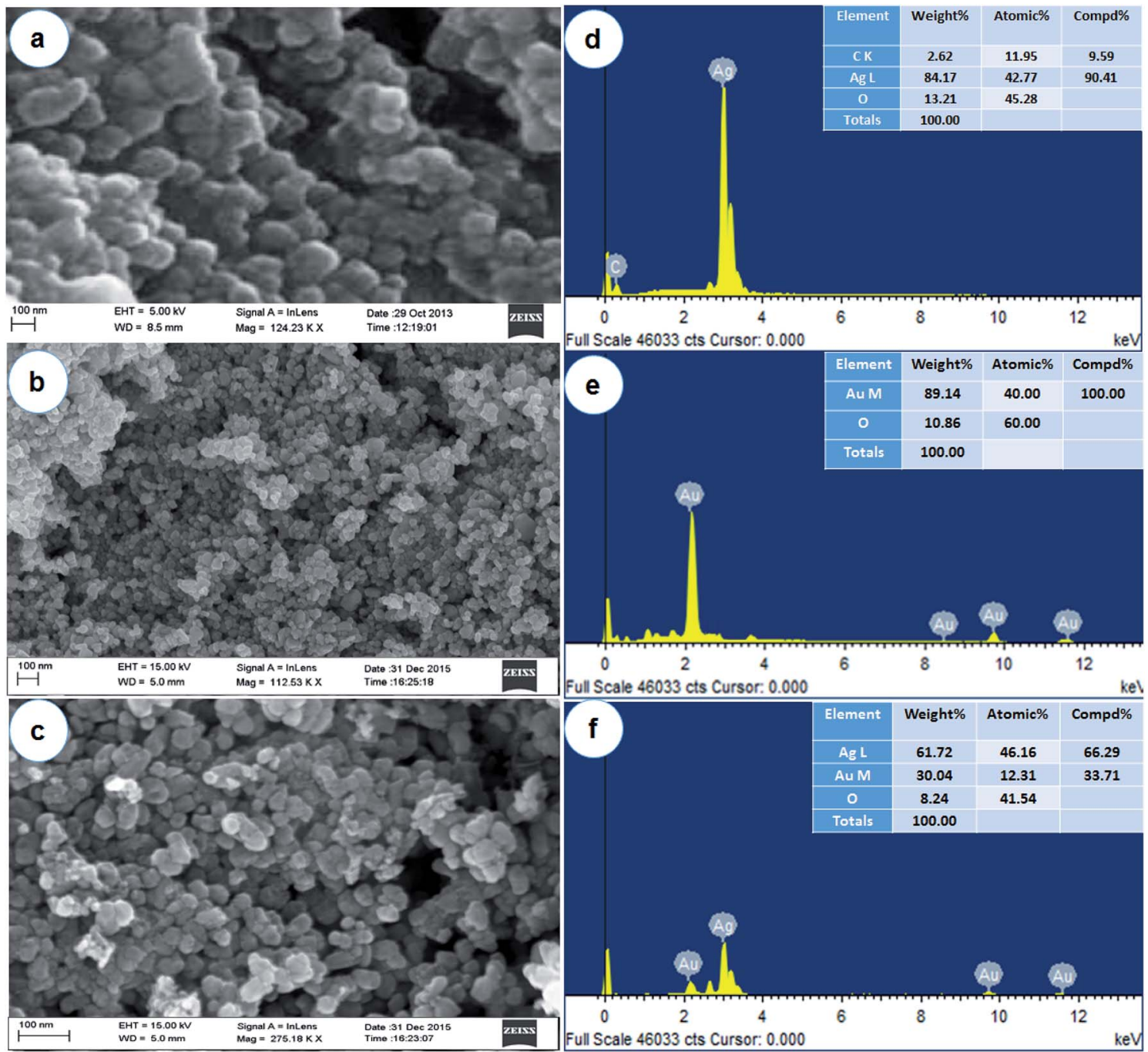

Fig. 1 Surface structure analysis by FE-SEM ( $a$ - AgNPs; b - AuNPs; c - Ag/AuNPs) and EDX (d - AgNPs; e - AuNPs; $f$ - Ag/AuNPs) spectra of synthesised nanoparticles. 

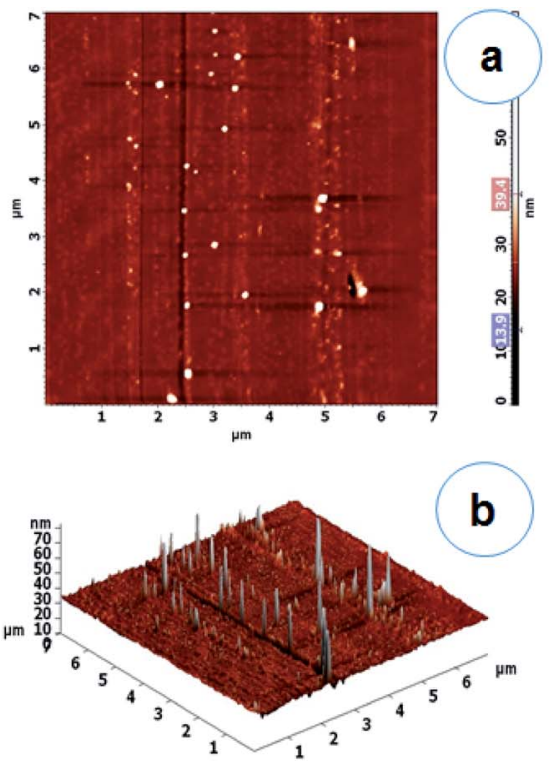
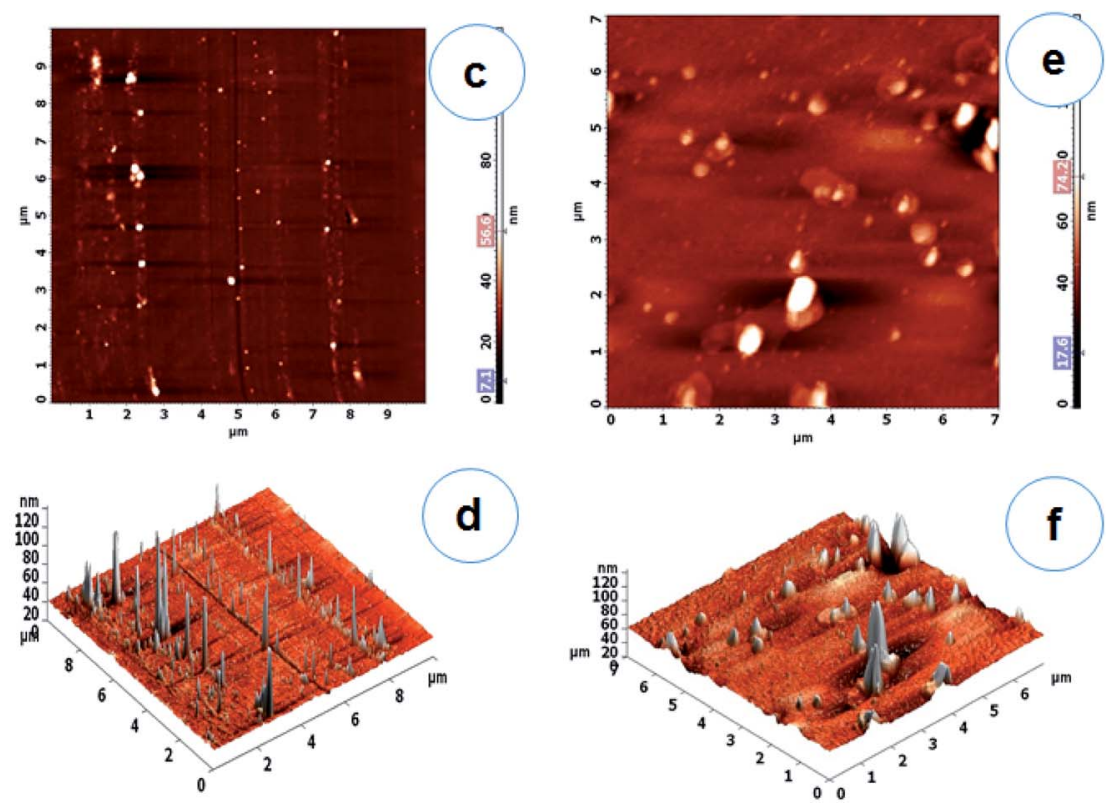

Fig. 2 AFM 2D \& 3D topography images ( $a, b-A g N P s ; c, d-A u N P s ; ~ e, f-A g / A u N P s)$.

has also led to the emergence of resistance to classical chemotherapies. Surveillance of drug resistance reported that bacteria expressing $\beta$-lactamases have drained an attention of modern researchers due to resistance to the broad range of $\beta$-lactams including third-generation cephalosporin derivatives. Nosocomial infections caused by these organisms have inadequate treatment options. ${ }^{32}$ Thus, a promising alternative to the microbial resistance scenario is the use of nanomaterials in the treatment of infectious diseases and their control. In this regard, metallic nanoparticles are particularly interesting because of their selectivity, specificity and versatility of incorporation into different biomolecules. Compared with antibiotic production, syntheses of antimicrobial nanoparticles are more cost-effective. Moreover, nanoparticles usually have a prolonged shelf-life and some of them can withstand extreme conditions, such as high-temperature sterilization, under which conventional antibiotics are inactivated. ${ }^{33}$ Therefore, nanoparticles can be used for both in vivo and in vitro biomedical research and applications. ${ }^{34}$ Apart from these applications, noble metals like $\mathrm{Ag}$ and Au showed potential uses in the field of medicine due to their antimicrobial activities and therefore used in many antimicrobial formulations. ${ }^{35,36}$

With these views, the present study is focused on the biosynthesis of AgNPs, AuNPs and Ag/AuNPs nanoparticles by using an extremophilic actinobacterium, Streptomyces sp. B5 using bio-reduction process. Aqueous $\mathrm{Ag}$ and $\mathrm{Au}$ ions, which were exposed to the biomass of actinobacterial strain, were reduced to form stable $\mathrm{Ag}, \mathrm{Au}$ and $\mathrm{Ag} / \mathrm{Au}$ nanoparticles under optimized conditions. After that, the nanoparticles were systematically characterized. ${ }^{21}$ The field emission scanning electron microscopy (FE-SEM) and atomic force microscopic (AFM) analysis were carried out to understand the surface morphology and topographic features of the metal and its alloy nanoparticles. FE-SEM observation showed the surface morphologic characteristics of AgNPs, AuNPs and their alloy nanoparticles. Based on the results, most of the nanoparticles were observed in a spherical shape (Fig. 1a-c). Energy Dispersive $\mathrm{X}$-ray Spectroscopy (EDX) is a very useful technique, to detect the metal ions in the samples by using metallic signals. Fig. 1d-f, showed the EDX analysis of AgNPs, AuNPs and their alloy nanoparticles. The strong $\mathrm{Ag}$ and Au signals confirmed the presence of metallic $\mathrm{Ag}$ and Au nanoparticles and their crystalline nature. Together with signals from $\mathrm{O}$ and $\mathrm{C}$ atoms were observed in the EDX analysis of the synthesised nanoparticles. The $\mathrm{O}$ and $\mathrm{C}$ signals were likely caused by X-ray emission from the carbon coated grid used in the EDX analysis. Comparable results have been reported for AgNPs, AuNPs and Ag/AuNPs fabricated using different microorganisms. ${ }^{37-41}$ Emission of energies by Ag and $\mathrm{Au}$ were characterized by the peaks obtained in the spectrum which confirms the presence of elements Ag and Au in the alloy sample. The results were closely similar to Tripathi et $a l .^{42}$ The specified topographic features of the biosynthesised nanoparticles were investigated by AFM analysis. The surface morphology of the samples can be better visualized and understood by their respective $2 \mathrm{D}$ and $3 \mathrm{D}$ topographic views. Fig. 2 showed the AFM 2D and 3D images of AgNPs, AuNPs and Ag/AuNPs. Similarly, Sadhasivam et al. ${ }^{37}$ reported the SEM and AFM observations of Streptomyces sp. mediated synthesis of AgNPs and Srivastava et al. ${ }^{43}$ studied that AFM analysis of biogenic synthesised gold nanoparticles by Escherichia coli K12. The same kind of observations was noted in this study.

DLS is used to monitor the particle size and aggregation state of the nanoparticle dispersion in solution. DLS histogram results revealed that the average particles sizes are found to be $30.5 \mathrm{~nm}$ (AgNPs), $14.5 \mathrm{~nm}$ (AuNPs) and $41.5 \mathrm{~nm}$ (Ag/AuNPs) respectively (Fig. 3a-c).$^{21}$ Similarly, the stability of nanoparticles can be obtained either electrostatic/charge stabilization or polymeric stabilization. Electrostatic stabilization is based on the formation of a charged layer through adsorption of ionic groups on the 

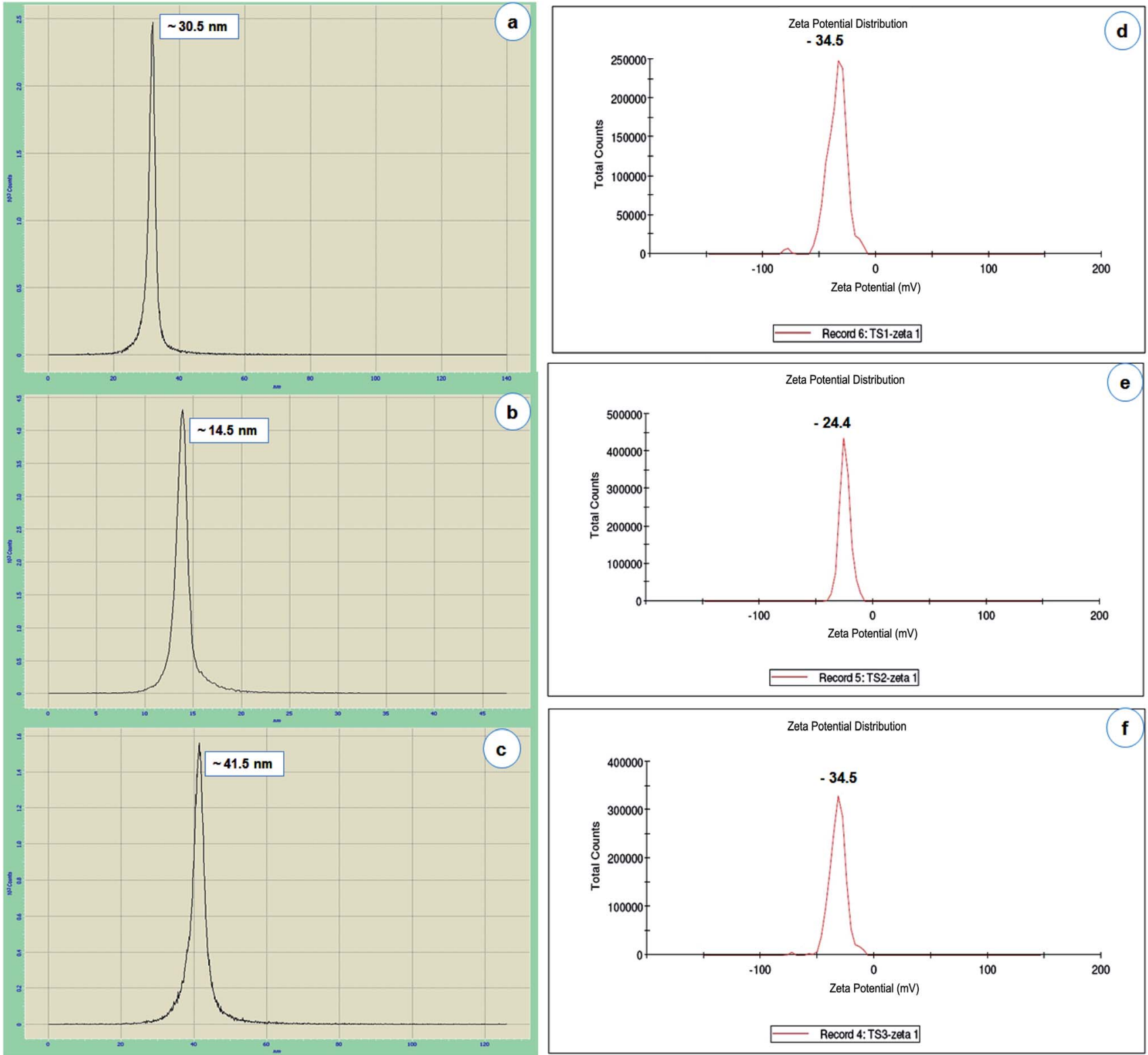

Fig. 3 Particle size histogram of AgNPs (a), AuNPs (b) and Ag/AuNPs (c). Zeta potential pattern of the AgNPs (d), AuNPs (e) and Ag/AuNPs (f).

nanoparticle surface, which leads to prevent the particle aggregation due to the influence of repulsive force among each other. ${ }^{44}$ Based on the concept, zeta potential analysis is also carried out to detect the surface charges acquired by $\mathrm{Ag}, \mathrm{Au}$ and $\mathrm{Ag} / \mathrm{Au}$ nanoparticles. Zeta potential of synthesised nanoparticles is found to be $-34.5 \mathrm{mV}$ (AgNPs), -24.4 $\mathrm{mV}$ (AuNPs) and $-31.8 \mathrm{mV}$ (Ag/ AuNPs), which indicate that $\mathrm{Ag}$ and alloy nanoparticles are highly stable. But, AuNPs is relatively stable in nature (Fig. 3d-f). Similarly, various research groups were effectively reported that the DLS and zeta-potential analysis of biosynthesised Ag, $\mathrm{Au}$ and $\mathrm{Ag} / \mathrm{Au}$ alloy nanoparticles. ${ }^{42,45,46}$

\section{Antimicrobial activity}

The antibiotic effect of nanoparticles was size and dosedependent and was more pronounced against Gram-negative bacteria than Gram-positive organisms. In this study also, the antibacterial activity of the biosynthesized $\mathrm{Ag}, \mathrm{Au}$ and $\mathrm{Ag} / \mathrm{Au}$ alloy nanoparticles were tested against human bacterial pathogens such as, Staphylococcus aureus (NCIM 2079), Bacillus subtilis (NCIM 2063), Klebsiella pneumoniae (NCIM 2706), Escherichia coli (NCIM 2256), Pseudomonas aeruginosa (NCIM 5031), Serratia marcescens (NCIM 5246) and fish pathogens such as, Aeromonas hydrophila (NCIM 5286), Providencia vermicola (MTCC 5578) respectively. The zone of inhibition in antibacterial activity against Gram-positive bacteria was in the range of $8.33 \mathrm{~mm}$ in diameter and Gram-negative bacteria from 7.66 to $15.16 \mathrm{~mm}$ (Table $1 \&$ S-Fig. $1 \dagger$ ). The antibacterial activity results clearly showed that $\mathrm{Ag}, \mathrm{Au}$ and $\mathrm{Ag} / \mathrm{Au}$ alloy nanoparticles, synthesised in this study completely dominate the inhibition of Gram-negative bacterial growth than Gram-positive bacteria. 


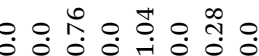
$H+H+H+H+H$ 우 00.000

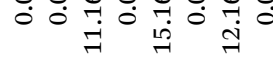

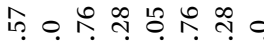
$\circ 0000000$ $H+H+H+H+H$

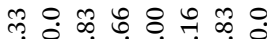

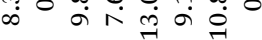

○ㅇำ $H+H+H+H+H$

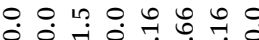

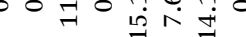

ণ 0000000 H H H H H H H $0 \div \infty \circ$ 누 $\infty \approx$ ○ें

in 0000000 H H H H H H H H

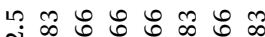
न

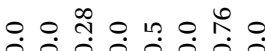
H H H H H H H H

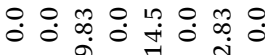

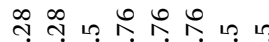
0000000 $H+H+H+H+H$

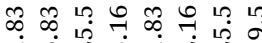
ㅁำ

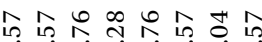
○ं $\mathrm{H} H \mathrm{H} H \mathrm{H} H \mathrm{H} H$ $m: 08000$ సิ ปิ่

$\wedge \stackrel{\infty}{\infty} 010$

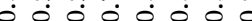
$H+H+H+H+H$

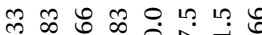

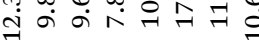

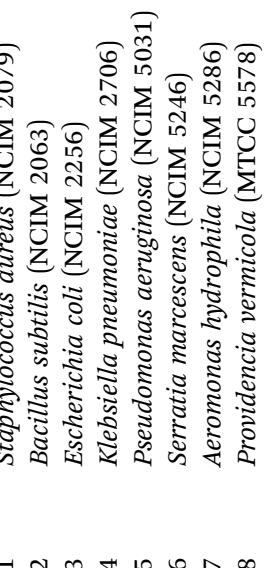

Additionally, the FE-SEM images clearly show that the morphologically induced changes like rupture of the cell membrane, cell shrinkage, aggregation of bacterial cells, etc. in AgNPs and Ag/AuNPs treated samples, whereas in control cells no changes were observed. EDX analysis also confirmed the presence of strong $\mathrm{Ag}$ and $\mathrm{Au}$ metallic signals in treated cells. Other minor signals like $\mathrm{C}, \mathrm{O}, \mathrm{Cl}, \mathrm{Mg}$ and $\mathrm{P}$ were observed due to the bacterial biomolecules. Cu signal raised from the copper grid was used during analysis (Fig. 4). Subsequently, data from this study indicated that the antibacterial activity of synthesized nanoparticles depends upon their size, shape and composition. ${ }^{47}$ Tabrizi et al. ${ }^{48}$ compared the antibacterial potential of Ag, $\mathrm{Au}$ and $\mathrm{Ag} / \mathrm{Au}$ alloy nanoparticles in different molar ratio. The alloys containing the $\mathrm{Ag}$ and $\mathrm{Au}$ ratio of $3: 1$ showed better activity than all the tested materials against $E$. coli. Unlike commercial antibiotics, nanoparticles do not exhibit their effects in a single specific way. Combinations of cellular mechanisms such as disruption of cell morphology, inactivation of vital cellular enzymes and proteins, DNA condensation, ${ }^{\mathbf{4 9}}$ depletion of ATP, loss of DNA replication, ${ }^{50}$ protein denaturation, ${ }^{51}$ accumulation at lethal concentration in cell, inhibition of ribosome interaction, ${ }^{52}$ generation of reactive oxygen species (ROS), oxidative stress, and modulation of cellular signaling ${ }^{53}$ make nanoparticles as typical target for a broad range of pathogens (Fig. 4k). Various studies that highlighted the antimicrobial properties of nanoparticles against bacteria, fungi and viruses are very common and have been explored extensively. Though, the combination of noble metal nanoparticles and drugs traditionally used in the treatment of these pathogens is an important method for controlling microbial resistance. ${ }^{\mathbf{1 0}}$ Development of resistance to nanoparticles is difficult because these materials act on different stages of the microbial metabolism.

Fungal mediated diseases contribute significantly to increased morbidity and mortality rates in immunosuppressed patients, ${ }^{54}$ especially cases of cancer, HIV, transplanted organs, and individuals undergoing long-term treatment with antifungal drugs. ${ }^{55}$ Likewise, implementation of medical devices such as central and peripheral vein catheters used for the treatment of patients with hemodialysis, chemotherapy and parenteral nutrition, contributes significant colonisation and fungal invasion by Candida spp. ${ }^{56}$ In this study, all the nanoparticles showed notable inhibition on Candida albicans with zone size of $15 \mathrm{~mm}(\mathrm{Ag}), 10.83 \mathrm{~mm}(\mathrm{Au}), 12.33 \mathrm{~mm}(\mathrm{Ag} / \mathrm{Au})$ and Candida glabrata with $15.83 \mathrm{~mm}$ (Ag), $14.5 \mathrm{~mm}$ (Ag/Au) respectively. The AuNPs do not show any inhibition zone against Candida glabrata (Table $2 \&$ S-Fig. $2 \dagger$ ). Different studies support the antifungal effect of metal nanoparticles including $\mathrm{Ag}$ and $\mathrm{Au}$, against Candida spp. ${ }^{57,58}$ Interestingly, Nagaonkar and $\mathrm{Rai}^{59}$ stated the anti-candidal potential of $\mathrm{Ag} / \mathrm{Au}$ nanoparticles against a wide range of Candida species.

Routine microbiological tests such as agar diffusion, MIC and $\mathrm{MBC}$ were commonly used to assess the antibacterial effect. Among, MIC and MBC methods used serial dilutions of a solution to determine the lowest concentration of material that would still show antibacterial properties. ${ }^{60}$ In this study, AgNPs showed the MIC value of $6.25 \mu \mathrm{g} \mathrm{ml}^{-1}$ against Escherichia coli 


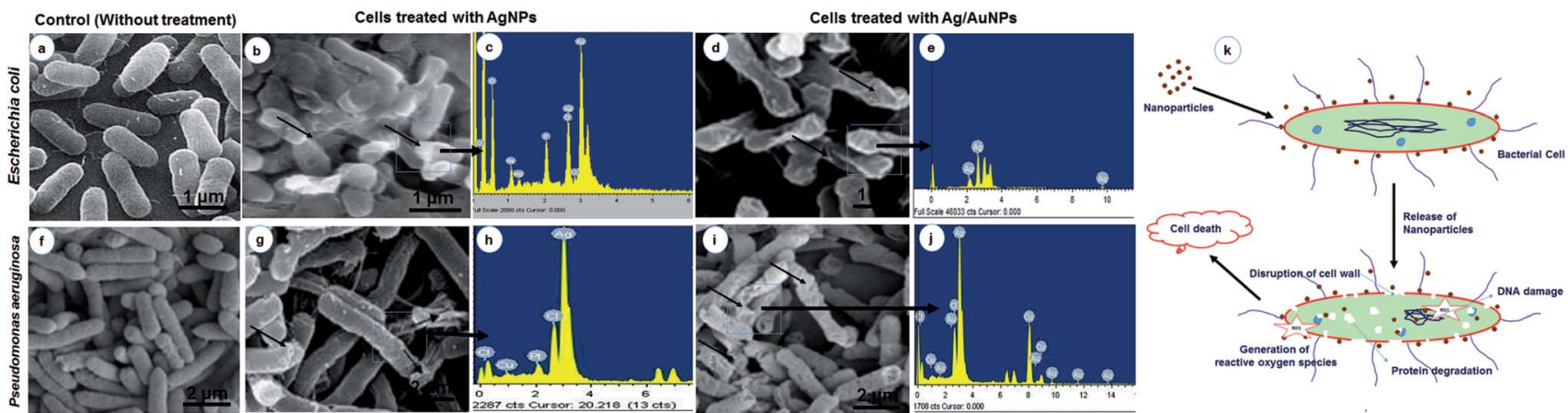

Fig. 4 FE-SEM analysis of control and NPs treated bacterial cultures with EDX analysis (a - E. coli control, b) E. coli treated with AgNPs, (c) EDX analysis of AgNPs treated, (d) E. coli treated with Ag/AuNPs, (e) EDX analysis of Ag/AuNPs treated, (f) P. aeruginosa control, (g) P. aeruginosa treated with AgNPs, (h) EDX analysis of AgNPs treated, (i) P. aeruginosa treated with Ag/AuNPs, (j) EDX analysis of Ag/AuNPs treated and (k) Schematic diagram of the mechanistic aspects of the antibacterial action representing ROS generation induced by nanoparticles.

Table 2 Antifungal activity of synthesised and standard nanoparticles

Zone of inhibition (diameter in millimetre) ${ }^{a}$ at $50 \mu \mathrm{g} \mathrm{mL}^{-1}$

\begin{tabular}{|c|c|c|c|c|c|c|c|c|c|c|}
\hline S. no. & $\begin{array}{l}\text { Test } \\
\text { pathogens }\end{array}$ & $\mathrm{AgNO}_{3}$ & $\mathrm{HAuCl}_{4}$ & $\begin{array}{l}\mathrm{AgNO}_{3}+ \\
\mathrm{HAuCl}_{4}\end{array}$ & STD AgNPs & STD AuNPs & $\begin{array}{l}\text { STD } \\
\text { Ag/AuNPs }\end{array}$ & AgNPs & AuNPs & $\mathrm{Ag} / \mathrm{AuNPs}$ \\
\hline 1 & $\begin{array}{l}\text { Candida } \\
\text { albicans }\end{array}$ & $9.83 \pm 0.28$ & $23.5 \pm 0.5$ & $21.66 \pm 0.57$ & $13.16 \pm 0.76$ & $11.83 \pm 0.76$ & $7.83 \pm 0.28$ & $15.0 \pm 0.5$ & $10.83 \pm 0.28$ & $12.66 \pm 0.28$ \\
\hline 2 & $\begin{array}{l}\text { Candida } \\
\text { glabrata }\end{array}$ & $11.0 \pm 0.5$ & $19.66 \pm 0.28$ & $23.5 \pm 0.5$ & $14.83 \pm 0.76$ & $11.83 \pm 0.28$ & $8.16 \pm 0.28$ & $15.83 \pm 0.28$ & $0.0 \pm 0.0$ & $14.5 \pm 0.5$ \\
\hline
\end{tabular}

Table 3 Average body weight of the selected animals ${ }^{a}$

\begin{tabular}{llllll}
\hline Observation & $\begin{array}{l}\text { Only wound } \\
\text { (control) }[\mathrm{G} \mathrm{I}]\end{array}$ & $\begin{array}{l}\text { Wound + standard } \\
\text { drug }[\mathrm{G} \mathrm{II}]\end{array}$ & $\begin{array}{l}\text { Wound + AgNPs } \\
{[\mathrm{G} \mathrm{III}]}\end{array}$ & $\begin{array}{l}\text { Wound + AuNPs } \\
{[\mathrm{G} \mathrm{IV}]}\end{array}$ & $\begin{array}{l}\text { Wound + Ag/AuNPs } \\
{[\mathrm{G} \mathrm{V}]}\end{array}$ \\
\hline Body weight & $170.12 \pm 1.807$ & $182.43 \pm 2.617$ & $180.75 \pm 2.110$ & $181.5 \pm 1.773$ & $181.5 \pm 1.732$ \\
${ }^{a}$ Values are expressed as mean \pm SEM $(n=3)$. & & &
\end{tabular}

(NCIM 2256), Pseudomonas aeruginosa (NCIM 5031) and Candida albicans. Similarly, AuNPs showed, $6.25 \mu \mathrm{g} \mathrm{ml}$ against Pseudomonas aeruginosa (NCIM 5031) and Ag/AuNPs exhibited the MIC value of $6.25 \mu \mathrm{g} \mathrm{m} \mathrm{m}^{-1}$ against Escherichia coli (NCIM 2256), Pseudomonas aeruginosa (NCIM 5031) and Candida albicans. The AgNPs showed the MBC value of $12.50 \mu \mathrm{g} \mathrm{ml}^{-1}$ against Escherichia coli (NCIM 2256) and Pseudomonas aeruginosa (NCIM 5031). The AuNPs exhibited $12.50 \mu \mathrm{g} \mathrm{ml}^{-1}$ against Pseudomonas aeruginosa (NCIM 5031) and alloy nanoparticles showed the MBC value of $12.50 \mu \mathrm{g} \mathrm{ml}$ against Escherichia coli (NCIM 2256) and Pseudomonas aeruginosa (NCIM 5031). (S-Table $1 \dagger$ ). Similarly, Krishnan et al. ${ }^{61}$ reported that MIC and MBC of AgNPs against E. faecalis were determined by microdilution method and was found to be effective at $5 \mathrm{mg} \mathrm{ml}^{-1}$. The MIC values of $\mathrm{Ag}$ and $\mathrm{Au}$ nanoparticles against $P$. aeruginosa and $B$. subtilis were found as, 10 $\mu \mathrm{g} \mathrm{ml} \mathrm{m}^{-1}$ and the MBC have been demonstrated for two clinical strains $P$. aeruginosa and B. subtilis in concentrations of 140 and $170 \mu \mathrm{g} \mathrm{ml}{ }^{-1}$, respectively. ${ }^{62}$

Salehi et al. ${ }^{63}$ studied the MIC and MBC of Ag/Au nanoparticles by broth microdilution method. The results showed that $10 \mathrm{ppm}$ nanocomposite reasonably killed the tested bacteria, Pseudomonas aeruginosa. Based on the results, metal and its alloy nanoparticles synthesized in the present study showed an extensive MIC and MBC on tested bacterial pathogens. Environmental Protection Agency (EPA) has established a chronic oral Reference Dose (RfD) of 5 micrograms ( $\mu \mathrm{g}$ ) of Ag (or) Au per kilogram (kg) of body weight per day ( $5 \mu \mathrm{g}$ per $\mathrm{kg}$ per day). The Occupational Safety and Health Administration (OSHA) and the Mine Safety and Health Administration (MSHA) currently enforce a Permissible Exposure Limit (PEL) of $0.01 \mathrm{mg} \mathrm{m}^{-3}$ for metallic and soluble Ag compounds. ${ }^{64}$ MIC and MBC of metal and their alloy nanoparticles against tested pathogens were found to be $6.25 \mu \mathrm{g} \mathrm{ml} l^{-1}$ and $12.50 \mu \mathrm{g} \mathrm{ml}^{-1}$ in this study. Therefore the level drops well within the safety zone for in vivo applications. 
Table 4 Percentage of wound contraction in excision wound models ${ }^{a}$

\begin{tabular}{|c|c|c|c|c|c|}
\hline Day & $\begin{array}{l}\text { Only wound } \\
\text { (control) }[\mathrm{G} \mathrm{I}]\end{array}$ & $\begin{array}{l}\text { Wound + standard } \\
\text { drug }[\mathrm{G} \mathrm{II}]\end{array}$ & $\begin{array}{l}\text { Wound + AgNPs } \\
\text { [G III }]\end{array}$ & $\begin{array}{l}\text { Wound + AuNPs } \\
\text { [G IV] }\end{array}$ & $\begin{array}{l}\text { Wound + Ag/AuNPs } \\
{[\mathrm{G} \text { V] }}\end{array}$ \\
\hline $0^{\text {th }}$ day & $0.08 \pm 0.0002$ & $0.08 \pm 0.0001$ & $0.08 \pm 0.0$ & $0.08 \pm 0.0$ & $0.08 \pm 0.0001$ \\
\hline $3^{\text {rd }}$ day & $18.48 \pm 2.11$ & $30.73 \pm 1.20$ & $30.79 \pm 1.21$ & $23.49 \pm 1.25$ & $28.58 \pm 1.52$ \\
\hline $5^{\text {th }}$ day & $26.09 \pm 1.72$ & $33.64 \pm 0.88$ & $35.47 \pm 0.72$ & $30.22 \pm 1.52$ & $30.83 \pm 1.38$ \\
\hline $7^{\text {th }}$ day & $37.29 \pm 2.96$ & $43.86 \pm 3.53$ & $39.10 \pm 1.56$ & $37.58 \pm 2.51$ & $38.99 \pm 0.81$ \\
\hline $11^{\text {th }}$ day & $62.13 \pm 0.75$ & $66.79 \pm 1.21$ & $63.77 \pm 2.02$ & $62.83 \pm 3.16$ & $63.50 \pm 1.68$ \\
\hline $14^{\text {th }}$ day & $70.05 \pm 1.64$ & $73.93 \pm 4.46$ & $72.84 \pm 3.06$ & $70.92 \pm 1.41$ & $71.93 \pm 0.93$ \\
\hline $17^{\text {th }}$ day & $79.94 \pm 1.52$ & $84.14 \pm 0.52$ & $83.34 \pm 2.32$ & $77.21 \pm 1.02$ & $80.54 \pm 1.62$ \\
\hline $19^{\text {th }}$ day & $94.85 \pm 1.02$ & $98.16 \pm 2.07$ & $100.0 \pm 0.0$ & $96.58 \pm 0.86$ & $96.23 \pm 2.75$ \\
\hline $21^{\text {st }}$ day & $96.46 \pm 0.66$ & $98.76 \pm 1.28$ & $100.0 \pm 0.0$ & $97.58 \pm 0.58$ & $100.0 \pm 0.0$ \\
\hline
\end{tabular}

${ }^{a}$ Values are expressed as mean \pm SD for three animal.

\section{In vivo excision wound healing activity}

The current study hypothesized that $\mathrm{Ag}$ and $\mathrm{Au}$ nanoparticles could improve the healing of burn wounds initially on the basis of the known antimicrobial property of these nanoparticles. In the present study, the excision wound model was created in rats and treated with standard antibiotics, induced with fixed concentration of AgNPs, AuNPs and Ag/AuNPs based ointment. The average body weights of the tested animals in each group were determined (Table 3 ). These results suggested that $10 \%$ concentration of $\mathrm{Ag}$ and $\mathrm{Ag} / \mathrm{Au}$ based ointments heal the wound completely (100\%) within 19 and 21 days compared with standard ointment. In case of $\mathrm{Au}$ based ointments, 97.58\% was attained within 21 days (Table 4 \& 5).

The histopathological characteristics of the healed wounds on day 5 and day 21 after wounding are shown in Fig. $6 \& 7$. On the $5^{\text {th }}$ day, the group I animals were observed with ulcerated skin epidermis. Dermis showed dense neutrophilic exudates with karyorrhectic debris and mild edema. Group II animals exhibited with ulcerated skin epidermis and dermis showed dense infiltration of neutrophils, lymphocytes and macrophages and fibroblasts. Additionally, stroma showed edema. Group III animals' revealed skin with epidermis showed early reepithelialisation. Dermis showed necrosis and neutrophilic infiltrates. Group IV animals showed ulcerated skin epidermis and dermis showed granulation tissue composed of dense neutrophilic exudates with karyorrhectic debris and edema. Group V animals were observed with ulcerated skin epidermis and dermis showed abscess formation with a dense collection of neutrophils (Fig. 6). After $21^{\text {st }}$ day, the group I animals were observed with normal skin epidermis. Dermis showed fibro-collagenous stroma with scattered lymphoplasmacytic infiltrates. Group II animals exhibited with normal skin epidermis and dermis showed fibro-collagenous stroma with mild lymphoplasmacytic infiltrates and thin-walled vessels. Group III animals revealed normal skin epidermis and dermis showed fibro-collagenous stroma with lymphoplasmacytic infiltrates and thin-walled vessels. Group IV animals showed normal skin epidermis and dermis showed fibro-collagenous stroma with moderate lymphoplasmacytic infiltrates and thin-walled vessels. Group V animals were observed with normal skin epidermis and dermis showed fibro-
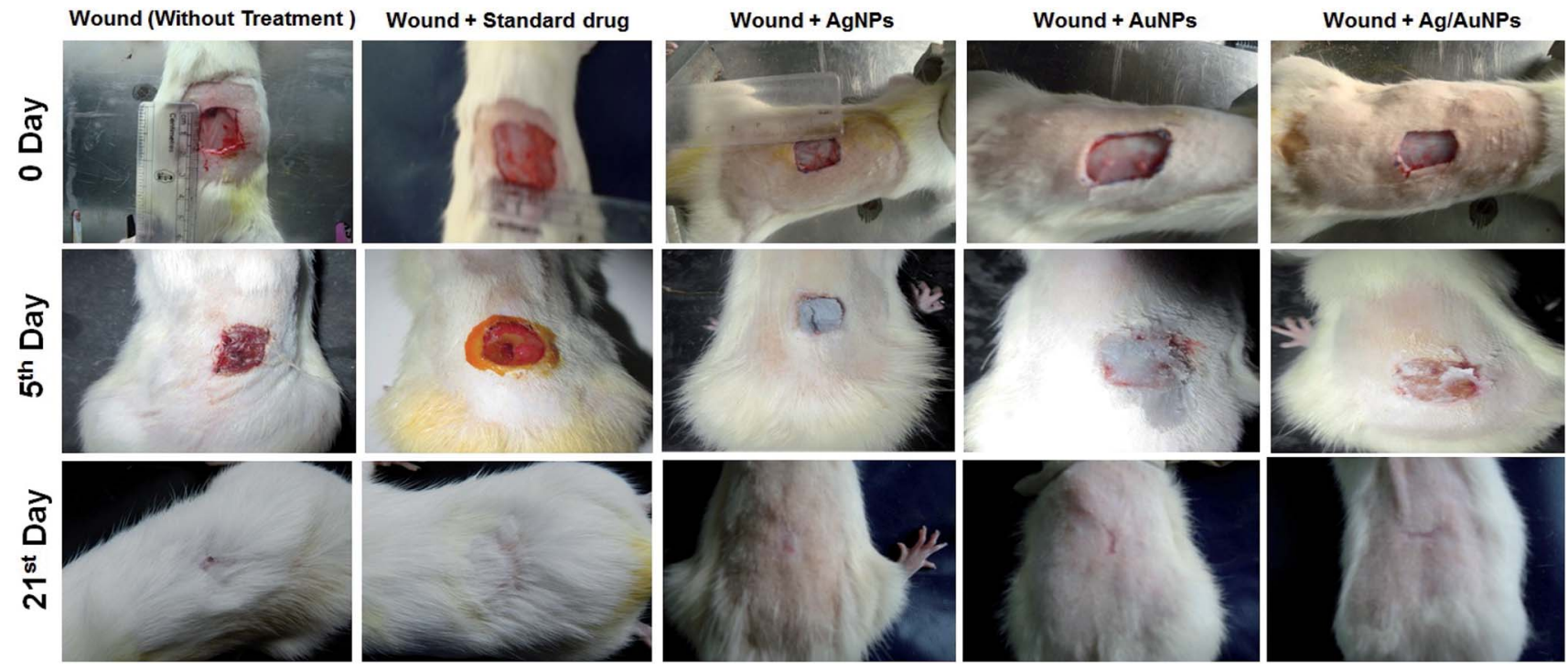

Fig. 5 Excision wound healing activity of standard drug and synthesised nanoparticles on Wistar rat models on $5^{\text {th }}$ and $21^{\text {st }}$ day. 

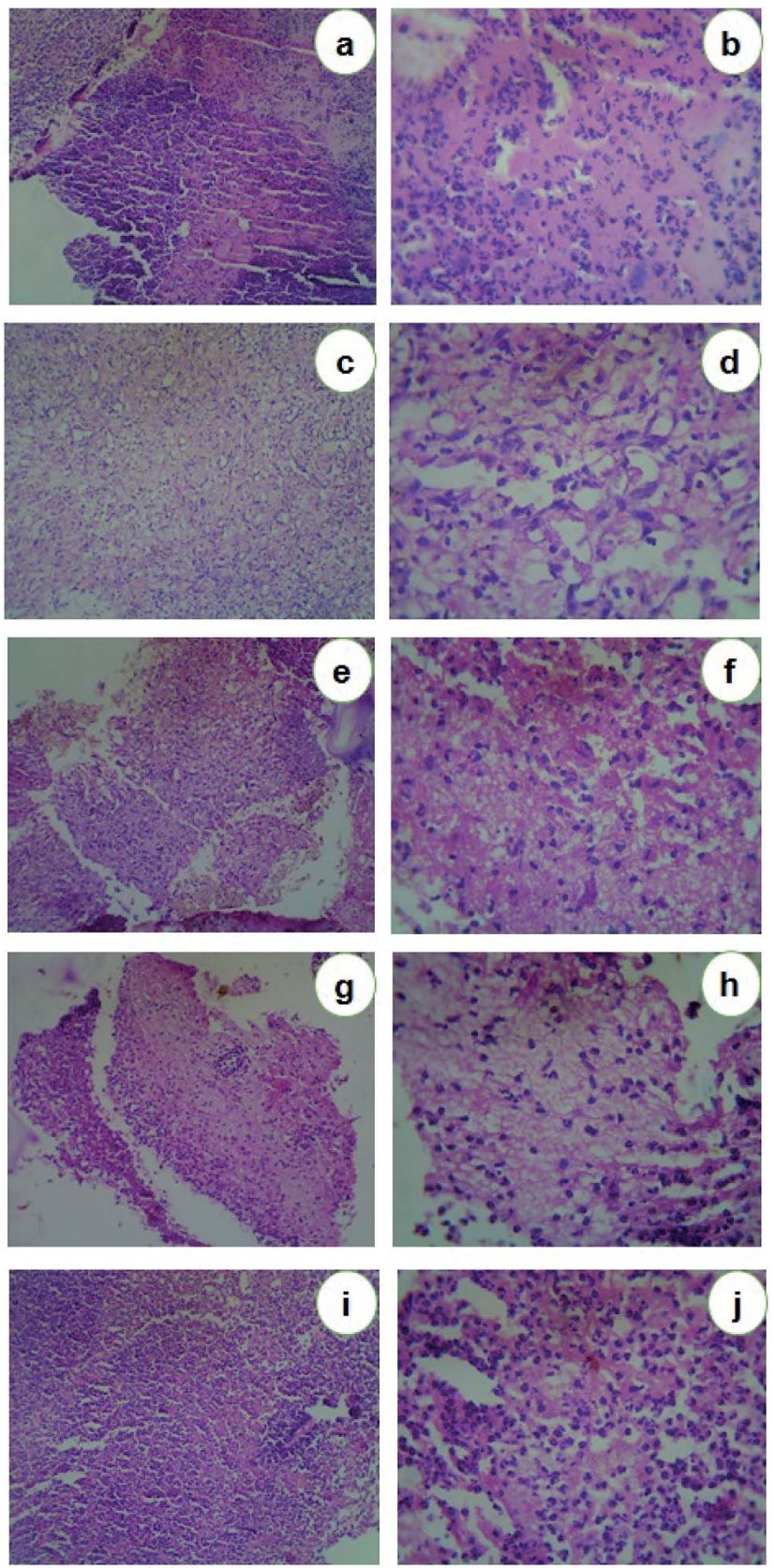

Fig. 6 Histopathological analysis of $5^{\text {th }}$ day wound skin samples. (a, b) Control animals (Group I); (c, d) animals treated with standard ointment (Group II); (e, f) animals treated with AgNPs (Group III); $(g, h)$ animals treated with AuNPs (Group IV); (i, j) animals treated with Ag/ AuNPs (Group V).

collagenous stroma with scattered lymphoplasmacytic infiltrates and thin-walled vessels (Fig. 7). Previously Rigo et al. ${ }^{65}$ synthesized AgNPs for the active healing of the wound of rats, evidenced by molecular and microscopic analysis. Naraginti et $a l .{ }^{66}$ reported that the excision wound healing in albino Wistar rats by topical application of green synthesized, formulated $\mathrm{Ag}$ and $\mathrm{Au}$ nanoparticles supported with histopathological analysis.

In wound repair process, restoration of the mechanical properties of tissue strength is a critical outcome. Measurement
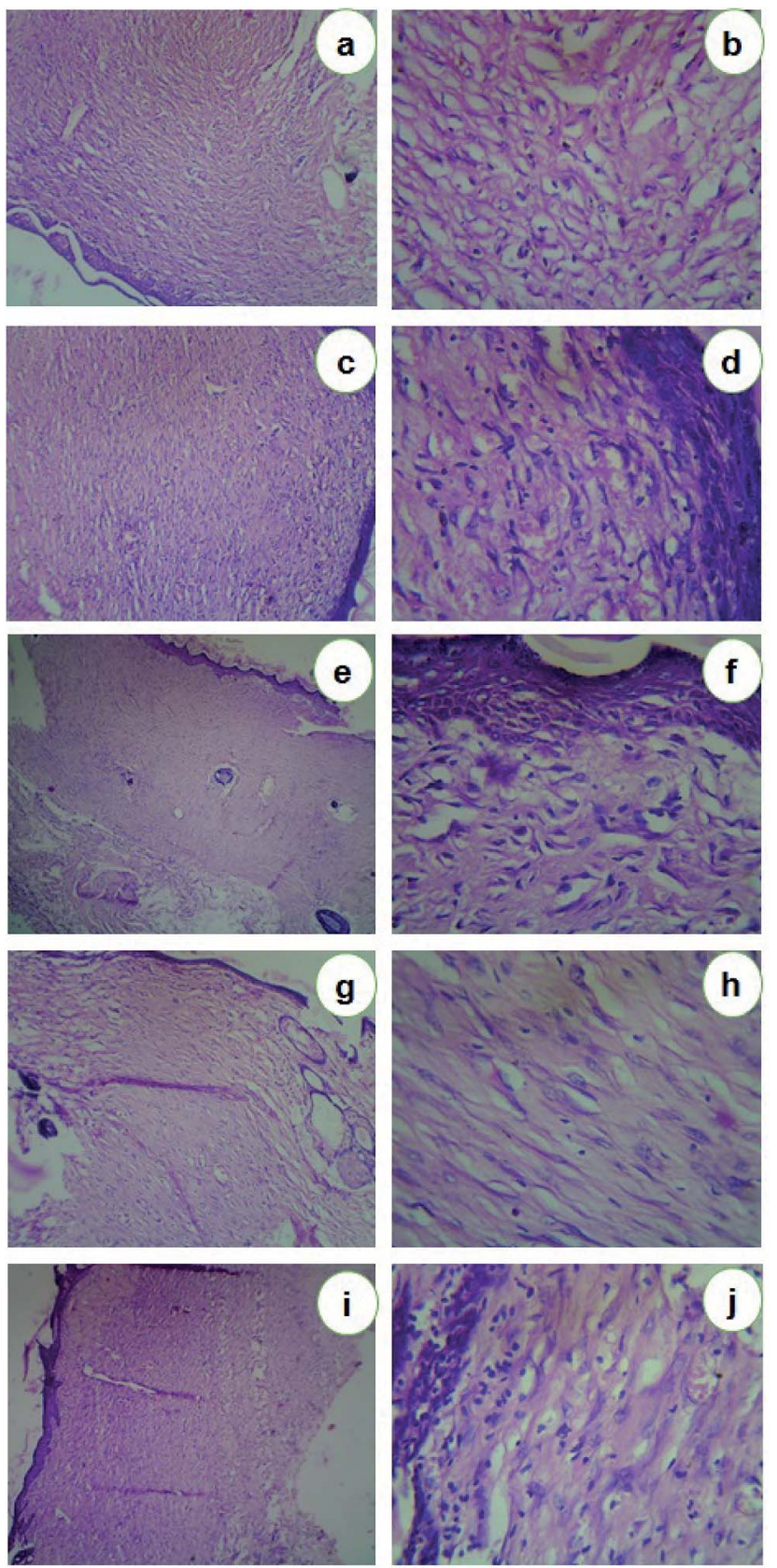

Fig. 7 Histopathological analysis of $21^{\text {st }}$ day wound skin samples. $(a, b)$ Control animals (Group I); (c, d) animals treated with standard ointment (Group II); (e, f) animals treated with AgNPs (Group III); (g, h) animals treated with AuNPs (Group IV); (i, j) animals treated with Ag/ AuNPs (Group V).

of wound strength provides a highly assessable estimation of the efficacy of the aggregate healing practice. Determination of various individual components of the healing phases can provide important insights about events operative during repair. However, if sufficient wound strength is not achieved the net effect may be wound failure. Factors that reduce wound repair can be evaluated according to the influence on the development of wound strength. In the present study, the healed wound skins of animals on the $21^{\text {st }}$ day showed 

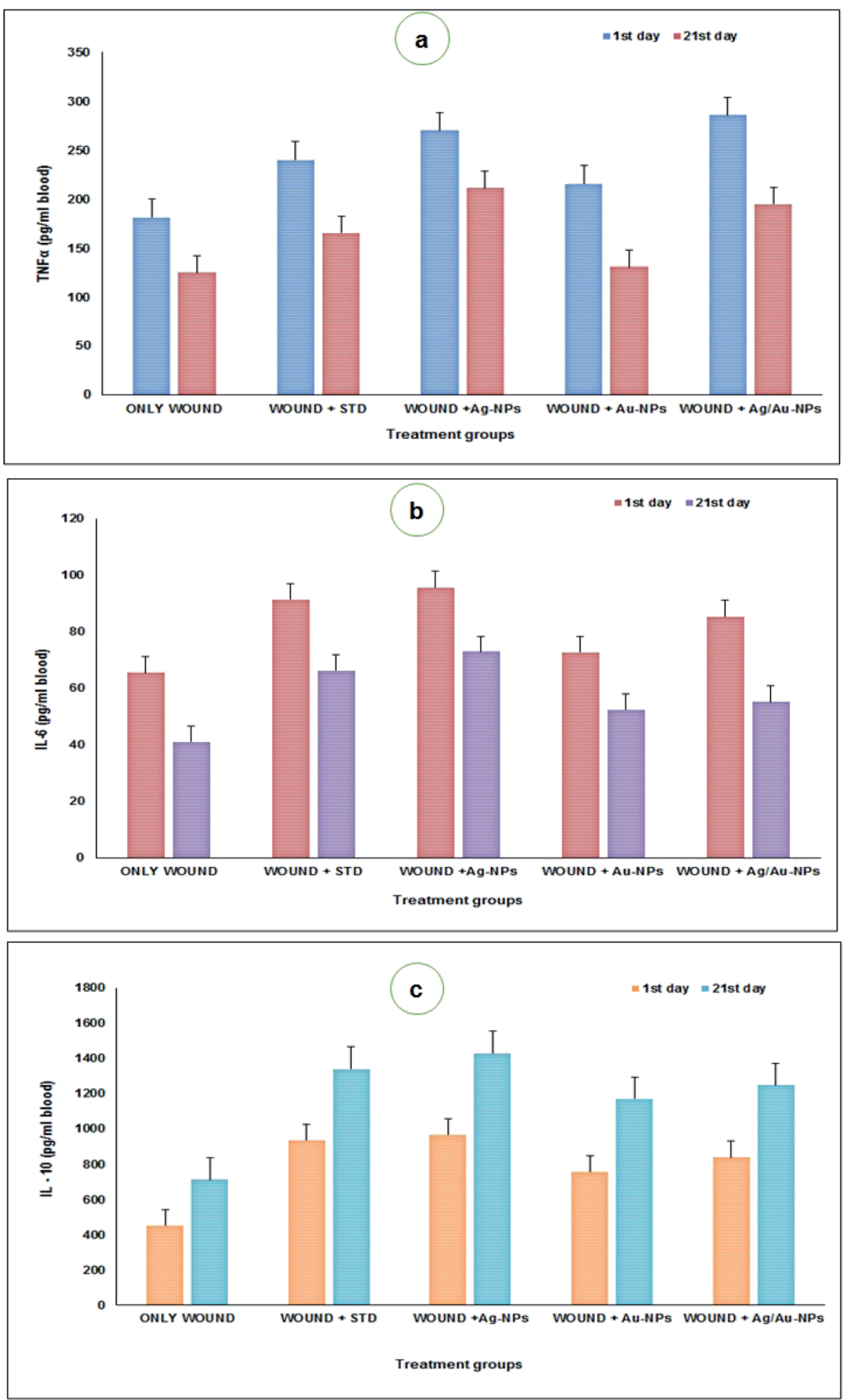

Fig. 8 Estimation of pro-inflammatory ( $\mathrm{a}-\mathrm{TNF} \alpha ; b-\mathrm{IL} 6)$ and anti-inflammatory (c - IL 10) cytokine induction in control and treated animals.

significantly higher elongation percentage than the animals at $5^{\text {th }}$ day after wounding. But, there is no significant difference was attained in control groups at $5^{\text {th }}$ and $21^{\text {st }}$ day of treatment (S-Fig. 3a $\dagger$ ). In case of other groups, the wound breaking strength was significantly increased upon continuous treatment (S-Fig. 3b-e†). Similarly, Bhaskar and Nithya ${ }^{67}$ and Nagar et al. ${ }^{68}$ studied the tensile strength of the healed scar during the wound healing process at different intervals. They also reported that the tensile strength was significantly increased upon treatments with different healing compounds.

Although inflammatory cytokines are crucial in initiating, sustaining, and regulating the post-injury response, these same 

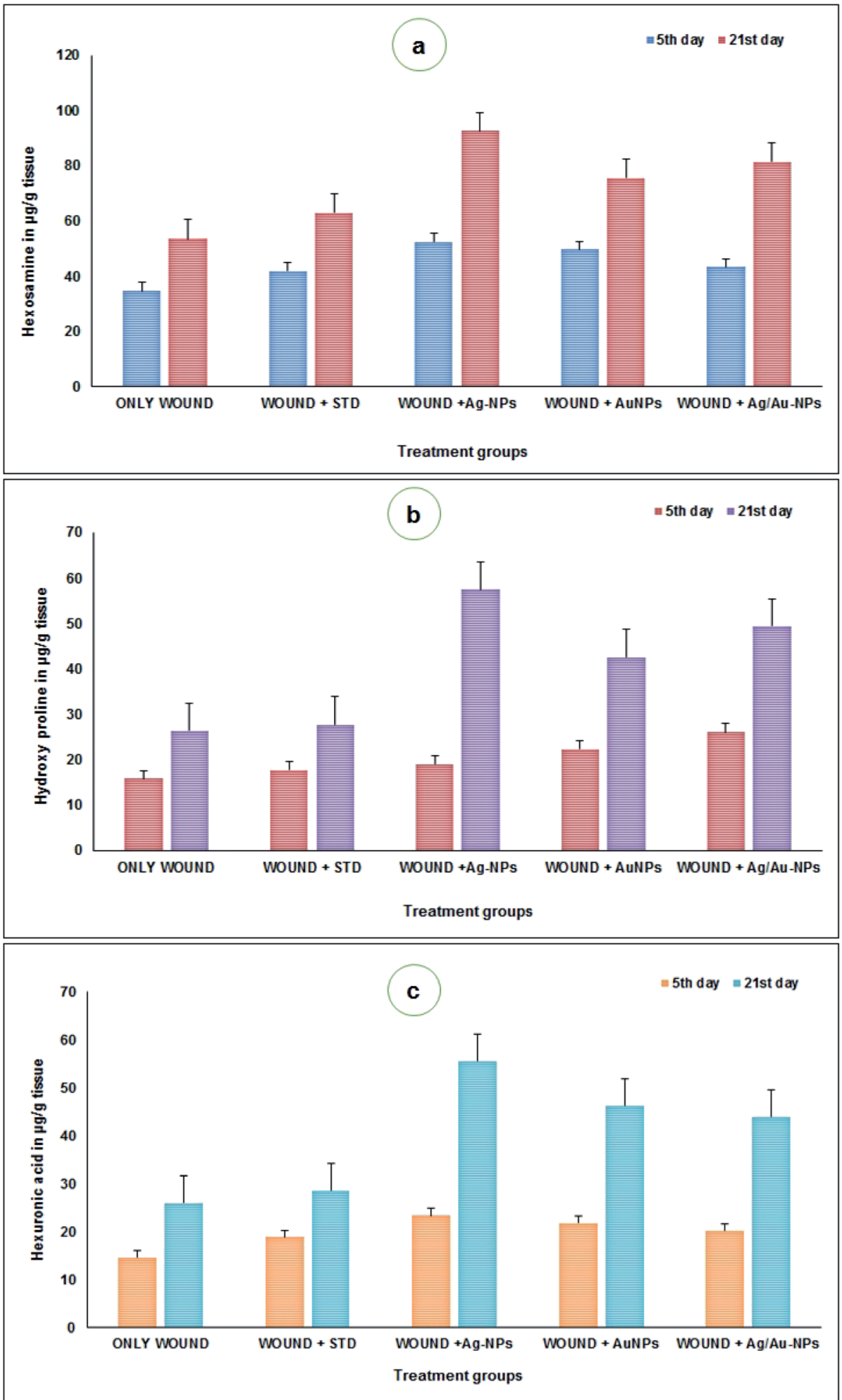

Fig. 9 Estimation of hexosamine (a), hydroxyproline (b) and hyaluronic acid (c) contents in control and treated animals.

molecules have been associated with impaired wound healing, abnormal scar formation, and uncontrolled inflammatory response. ${ }^{69,70}$ Besides, the pro-inflammatory cytokine IL-6 has been revealed to be a potent stimulator of fibroblast proliferation. ${ }^{71}$ The important role of IL-10 is regulating the expression of proinflammatory cytokines in wounds, leading to decreased matrix deposition and scar-free healing. ${ }^{72}$ After wounding, the $\mathrm{TNF} \alpha$ level in the animals at $21^{\text {st }}$ day was significantly lower (G1: 124.998, G2: 165.4, G3: 211.2, G4: 130.584, and G5: 194.896 pg $\mathrm{ml}^{-1}$ ) than the animals at $24 \mathrm{~h}$ of wounding (G1: 181.48, G2: 
240.314, G3: 270.02, G4: 215.792, and G5: $285.84 \mathrm{pg} \mathrm{ml}^{-1}$ ) respectively (Fig. 8a). At $24 \mathrm{~h}$ after wounding, the IL-6 level in the animal groups were significantly higher (G1: 65.528, G2: 91.504, G3: $95.756, \mathrm{G} 4: 72.788$ and G5: $84.424 \mathrm{pg} \mathrm{ml}^{-1}$ ) than the animals at after $21^{\text {st }}$ days of treatment (G1: 41.184, G2: 66.34, G3: 72.91, G4: 52.468 and G5: $55.268 \mathrm{pg} \mathrm{ml}^{-1}$ ) (Fig. 8b). The IL-10 level after wounding at $24 \mathrm{~h}$ in the animal groups showed significantly lower (G1: 453.204, G2: 935.15, G3: 966.9, G4: 757.432 and G5: $838.676 \mathrm{pg} \mathrm{ml}^{-1}$ ) than the animals treated at 21 days (G1: 711.07, G2: 1340.92, G3: 1430.016, G4: 1171.2 and G5: $1247.16 \mathrm{pg} \mathrm{ml}^{-1}$ ) (Fig. 8c). Pivodova et al. $^{73}$ revealed that the wound healing activity of AuNPs with estimation of inflammatory cytokines.

Collagen plays a vital role in the healing of wounds of skin and other tissues. There is an overall agreement that synthesis of collagenous constituents is required for restoration of physical strength of wounds. It is now also widely recognized that clarification of the defined role of collagen in the wound healing process requires not only information on the amount of collagen present during the healing process, but, in addition, data on the rate at which collagen is synthesized, deposited and resorbed. ${ }^{74}$ With this view, the quantity of collagenous constituents such as hexosamine, hydroxyproline and hyaluronic acid in healing wounds on different days (5 and 21) was estimated and presented in Fig. 9. The hexosamine content was significantly higher in the nitrofurazone ointment (day 5: $41.98 \mu \mathrm{g} \mathrm{g}^{-1}$; day 21: $63.16 \mu \mathrm{g} \mathrm{g}^{-1}$ of tissue) and nanoparticles treated groups (day 5: $52.6 \mu \mathrm{g} \mathrm{g}^{-1}$, day 21: $92.66 \mu \mathrm{g} \mathrm{g}^{-1}$ (Ag); day 5: $49.74 \mu \mathrm{g} \mathrm{g}^{-1}$, day 21: $75.66 \mu \mathrm{g} \mathrm{g}^{-1}(\mathrm{Au})$; day 5: $43.42 \mu \mathrm{g} \mathrm{g}^{-1}$, day 21: $81.5 \mu \mathrm{g} \mathrm{g}^{-1}$ of tissue) than in the control group (day 5: $34.78 \mu \mathrm{g} \mathrm{g}^{-1}$; day 21: $53.66 \mu \mathrm{g} \mathrm{g}^{-1}$ of tissue) (Fig. 9a). The hydroxyproline content was significantly lower on days 5 and 21 after wounding in the control group animals (day 5: $15.9 \mu \mathrm{g} \mathrm{g}^{-1}$; day $21: 26.5 \mu \mathrm{g} \mathrm{g}^{-1}$ of tissue) than in the nitrofurazone ointment (day 5: $17.88 \mu \mathrm{g} \mathrm{g}^{-1}$; day 21: $27.83 \mu \mathrm{g} \mathrm{g}^{-1}$ of tissue) and nanoparticles treated groups (day 5: $19.12 \mu \mathrm{g} \mathrm{g}^{-1}$, day 21: $57.5 \mu \mathrm{g} \mathrm{g}^{-1}(\mathrm{Ag})$ ) day 5: $22.48 \mu \mathrm{g} \mathrm{g}^{-1}$, day 21: $42.66 \mu \mathrm{g} \mathrm{g}^{-1}$ (Au); day 5: $26.18 \mu \mathrm{g} \mathrm{g}^{-1}$, day 21: $49.5 \mu \mathrm{g} \mathrm{g}^{-1}$ of tissue) respectively (Fig. 9b). The hyaluronic acid content was significantly higher on days 5 and 21 after wounding in the nitrofurazone ointment (day 5: $18.9 \mu \mathrm{g} \mathrm{g}^{-1}$; day 21: $28.66 \mu \mathrm{g} \mathrm{g}^{-1}$ of tissue) and nanoparticles treated groups (day 5: $23.43 \mu \mathrm{g} \mathrm{g}^{-1}$, day 21: $55.66 \mu \mathrm{g} \mathrm{g} \mathrm{g}^{-1}(\mathrm{Ag})$; day 5: $21.88 \mu \mathrm{g} \mathrm{g} \mathrm{g}^{-1}$, day 21: $46.33 \mu \mathrm{g} \mathrm{g}^{-1}$ (Au); day 5: $20.2 \mu \mathrm{g} \mathrm{g}^{-1}$, day 21: $44 \mu \mathrm{g} \mathrm{g}^{-1}$ of tissue) than in the control group (day 5: $14.65 \mu \mathrm{g} \mathrm{g}^{-1}$; day 21: $26 \mu \mathrm{g} \mathrm{g}^{-1}$ of tissue) (Fig. 9c). Similarly, Bhaskar and Nithya ${ }^{67}$ reported the increased levels of hexosamine, hydroxyproline and uronic acid contents in healing wounds on different day intervals upon treatments. Based on the available studies, this is the first report on the wound healing activity of biosynthesised $\mathrm{Ag} / \mathrm{Au}$ nanoparticles on rat models.

The exact mechanism involved in the wound healing activity of nanoparticles was not determined. However, nanoparticles like $\mathrm{Ag}$ and $\mathrm{Au}$, are excellent candidates to be used as antiinflammatory agents in various therapies. ${ }^{75}$ Advances in the field of nanoscience and technology, particularly the ability to formulate highly ordered nanoparticles of any shape and size, have controlled to the development of new biocidal agents.

\section{Conclusion}

To conclude, the present study documented the synthesis of Ag, $\mathrm{Au}$ and $\mathrm{Ag} / \mathrm{Au}$ alloy nanoparticles by using actinobacterial metabolites against in vitro antimicrobial (including antibacterial and antifungal) and in vivo excision wound healing activities on Wistar rat models. Characterization of NPs was done by using vital instrumental analysis. Based on the results, AgNPs and Ag/AuNPs actively inhibit the growth of Gramnegative bacterial pathogens and opportunistic Candida spp., Subsequently, both the NPs heal the excision wound within 21 days and exerted anti-inflammatory activity via inhibition of IL6 and TNF- $\alpha$ level than the standard. Additionally, the present study will definitely be a challenging to develop novel alloy nanoparticles based antimicrobial drugs and wound ointments for better alternative applications. This enhances our knowledge of the biological effects exerted by these precious metals and opens a new paradigm of medical research.

\section{Conflicts of interest}

There are no conflicts to declare.

\section{Acknowledgements}

The authors thank the Vice Chancellor and the Registrar of the Periyar University, Salem for providing all of the necessary facilities to carry out this work. One of the authors, T. Shanmugasundaram (INSPIRE Fellow, IF120708), wishes to express heartfelt thanks to DST, India for financial support and extending thanks to PSG IAS, Coimbatore for their kind help for the instrumentation analysis, $\mathrm{KMCH}$ College of Pharmacy for animal studies. The corresponding author (RB), thanks to the Department of Science and Technology (DST), New Delhi, India for sanctioning DST-FIST grant (Ref. No: SR/FST/LSI-640).

\section{References}

1 L. Conteh, T. Engels and D. H. Molyneux, Lancet, 2010, 375, 239.

2 R. B. McFee, Dis.-Mon., 2013, 59, 426.

3 Y. E. Cossart, Med. J. Aust., 2014, 201, S11.

4 C. J. L. Murray, Lancet, 2015, 385, 117.

5 T. P. Van Boeckel, S. Gandra, A. Ashok, Q. Caudron, B. T. Grenfell, S. A. Levin and R. Laxminarayan, Lancet Infect. Dis., 2014, 14, 742.

6 B. Rechel, M. Suhrcke, S. Tsolova, J. E. Suk, M. Desai, M. McKee, D. Stuckler, I. Abubakar, P. Hunter, M. Senek and J. C. Semenza, Health Pol., 2011, 103, 168.

7 A. Rocha-Buelvas, E. Trujillo-Montalvo, C. Hidalgo-Patiño and A. Hidalgo-Eraso, Colomb. Med., 2014, 45, 96.

8 M. Eandi and G. P. Zara, Int. J. Clin. Pract., Suppl., 1998, 95, 27.

9 T. J. John, L. Dandona, V. P. Sharma and M. Kakkar, Lancet, 2011, 377, 252. 
10 World Health Organization, http:/www.who.int/ mediacentre/news/releases/2017/bacteria-antibiotics-needed/ en/, 2017.

11 J. M. Conlon, J. Kolodziejek and N. Nowotny, Biochim. Biophys. Acta, Proteins Proteomics, 2004, 1696, 1.

12 D. Baram-Pinto, S. Shukla, A. Gedanken and R. Sarid, Small, 2010, 6, 1044.

13 S. Bhatt, P. W. Gething, O. J. Brady, J. P. Messina, A. W. Farlow, C. L. Moyes, J. M. Drake, J. S. Brownstein, A. G. Hoen, O. Sankoh, M. F. Myers, D. B. George, T. Jaenisch, G. R. Wint, C. P. Simmons, T. W. Scott, J. J. Farrar and S. I. Hay, Nature, 2013, 496, 504.

14 J. E. Paddle-Ledinek, Z. Nasa and H. J. Cleland, Plast. Reconstr. Surg., 2006, 117, 110S.

15 E. Ulkur, O. Oncul, H. Karagoz, E. Yeniz and B. Celikoz, Burns, 2005, 31, 874.

16 T. M. Oberyszyn, Front. Biosci., 2007, 12, 2993.

17 J. Tian, K. K. Wong, C. M. Ho, C. N. Lok, W. Y. Yu, C. M. Che, J. F. Chiu and P. K. Tam, ChemMedChem, 2007, 2, 129.

18 R. L. Lundblad, R. A. Bradshaw, D. Gabriel, T. L. Ortel, J. Lawson and K. G. Mann, Thromb. Haemostasis, 2004, 91, 851.

19 E. T. Wang, R. Sandberg, S. Luo, I. Khrebtukova, L. Zhang, C. Mayr, S. F. Kingsmore, G. P. Schroth and C. B. Burge, Nature, 2008, 456, 470.

20 J. S. Kim, E. Kuk, K. N. Yu, J. H. Kim, S. J. Park, H. J. Lee, S. H. Kim, Y. K. Park, Y. H. Park, C. Y. Hwang, Y. H. Kim, Y. S. Lee, D. H. Jeong and M. H. Cho, Nanomedicine, 2007, 3, 95.

21 T. Shanmugasundaram, M. Radhakrishnan, V. Gopikrishnan, K. Kadirvelu and R. Balagurunathan, Nanoscale, 2017, DOI: 10.1039/C7NR04979J.

22 M. M. R. Mollick, B. Bhowmick, D. Mondal, D. Maity, D. Rana, S. K. Dash, S. Chattopadhyay, S. Roy, J. Sarkar, K. Acharya and M. Chakrabortye, RSC Adv., 2014, 4, 37838.

23 Clinical and Laboratory Standards Institute, CLSI document M27-A3, P. A. Wayne, 2008.

24 J. N. de Almeida Junior, A. L. Motta, F. Rossi, E. Abdala, L. C. Pierrotti, A. S. G. Kono, M. D. P. Estevez Diz, G. Benard and G. M. B. D. Negro, Clinics, 2012, 67, 1229.

25 Clinical and Laboratory Standards Institute, CLSI publication M07-A8, P. A. Wayne, 2009.

26 M. Moideen, R. Varghese, E. K. Kumar and C. K. Dhanapal, Res. J. Pharm., Biol. Chem. Sci., 2011, 2, 643.

27 M. S. Fatouros, G. Vekinis, K. L. Bourantas, E. P. Mylonakis, A. S. Scopelitou, V. D. Malamou-Mitsis and A. M. Kappas, Eur. J. Surg., 1999, 165, 986.

28 J. F. Woessner Jr, Arch. Biochem. Biophys., 1961, 93, 440.

29 P. G. Johansen, R. D. Marshall and A. Neuberger, Biochem. J., 1960, 77, 239.

30 T. Bitter and H. M. Muir, Anal. Biochem., 1962, 4, 330.

31 A. J. Alanis, Arch. Med. Res., 2005, 36, 697.

32 G. A. Jacoby and L. S. Munoz-Price, N. Engl. J. Med., 2005, 352, 380.

33 A. J. Huh and Y. J. Kwon, J. Controlled Release, 2011, 156, 128.
34 F. Benyettou, R. Rezgui, F. Ravaux, T. Jaber, K. Blumer, M. Jouiad, L. Motte, J.-C. Olsen, C. Platas-Iglesias, M. Magzoub and A. Trabolsi, J. Mater. Chem. B, 2015, 3, 7237. 35 M. Rai, A. Yadav and A. Gade, Biotechnol. Adv., 2009, 27, 76. 36 M. E. B. Patrascu, C. Ungureanu, S. M. Iordache, I. R. Bunghez, N. Badea and I. Rau, J. Mater. Chem. B, 2014, 2, 3221.

37 S. Sadhasivam, P. Shanmugam and K. Yun, Colloids Surf., B, 2010, 81, 358.

38 S. Mukherjee, M. Dasari, S. Priyamvada, R. Kotcherlakota, V. S. Bollu and C. R. Patra, J. Mater. Chem. B, 2015, 3, 3820.

39 S. Senapati, A. Ahmad, M. I. Khan, M. Sastry and R. Kumar, Small, 2005, 1, 517.

40 I. U. Carmen, P. Chithra, Q. Huang, P. Takhistov, S. Liu and J. L. Kokini, Food Technol., 2003, 57, 24.

41 R. Mata, A. Bhaskaran and S. R. Sadras, Particuology, 2015, 24, 78.

42 R. M. Tripathi, R. K. Gupta, A. S. Bhadwal, P. Singh, A. Shrivastav and B. R. Shrivastav, IET Nanobiotechnol., 2015, 9, 178.

43 S. K. Srivastava, R. Yamada, C. Ogino and A. Kondo, Nanoscale Res. Lett., 2013, 8, 70.

44 R. A. Sperling and W. J. Parak, Philos. Trans. R. Soc., A, 2010, 368, 1333.

45 T. Y. Suman, S. R. Radhika Rajasree, C. Jayaseelan, R. Regina Mary, S. Gayathri, L. Aranganathan and R. R. Remya, Environ. Sci. Pollut. Res., 2016, 23, 2705.

46 R. Bhambure, M. Bule, N. Shaligram, M. Kamat and R. Singha, Chem. Eng. Technol., 2009, 32, 1036.

47 C. Baker, A. Pradhan, L. Pakstis, D. J. Pochan and S. I. Shah, J. Nanosci. Nanotechnol., 2005, 5, 244.

48 N. S. Tabrizi, M. Tazikeh and N. Shahgholi, Int. J. Green Nanotechnol., 2012, 4, 489.

49 W. Li, X. Xie, Q. Shi, S. Duan, Y. Ouyang and Y. Chen, BioMetals, 2011, 24, 135.

50 S. A. Kumar, Y. A. Peter and J. L. Nadaeu, Nanotechnology, 2008, 19, 495101.

51 I. Sondi and B. Salopek-Sondi, J. Colloid Interface Sci., 2004, 275, 177.

52 A. Dror-Ehre, H. Mamane, T. Belenkova, G. Markovich and A. Adin, J. Colloid Interface Sci., 2012, 339, 521.

53 L. Braydich-Stolle, S. Hussain, J. J. Schlager and M. C. Hofmann, Toxicol. Sci., 2005, 88, 412.

54 A. Panacek, M. Kolar, R. Vecerova, R. Prucek, J. Soukupova, V. Krystof, P. Hamal, R. Zboril and L. Kvitek, Biomaterials, 2009, 30, 6333.

55 J. C. Sardi, L. Scorzoni, T. Bernardi, A. M. Fusco-Almeida and M. J. Mendes Giannini, J. Med. Microbiol., 2013, 62, 10.

56 M. Mikulska, B. Del Bono, S. Ratto and C. Viscoli, Expert Rev. Clin. Immunol., 2012, 8, 755.

57 D. R. Monteiro, S. Silva, M. Negri, L. F. Gorup, E. R. de Camargo, R. Oliveira, D. B. Barbosa and M. Henriques, Lett. Appl. Microbiol., 2012, 54, 383.

58 I. A. Wani, S. Khatoon, A. Ganguly, J. Ahmed and T. Ahmad, Colloids Surf., B, 2013, 101, 243.

59 D. Nagaonkar and M. Rai, Adv. Mater. Lett., 2015, 6, 334. 
60 C. Estrela, C. R. A. Estrela, L. L. Bammann and J. D. Pecora, J. Endod., 2001, 27, 5.

61 R. Krishnan, V. Arumugam and S. K. Vasaviah, J. Nanomed. Nanotechnol., 2005, 6, 285.

62 M. Składanowski, M. Wypij, D. Laskowski, P. Golińska, H. Dahm and M. Rai, J. Cluster Sci., 2017, 28, 59.

63 A. H. Salehi, M. Montazer, T. Toliyat and M. Mahmoudi-Rad, J. Liposome Res., 2015, 25, 38.

64 P. L. Drake and K. J. Hazelwood, Ann. Occup. Hyg., 2005, 49, 575.

65 C. Rigo, L. Ferroni, I. Tocco, M. Roman, I. Munivrana, C. Gardin, W. R. L. Cairns, V. Vindigni, B. Azzena, C. Barbante and B. Zavan, Int. J. Mol. Sci., 2013, 14, 4817.

66 S. Naraginti, P. L. Kumari, R. K. Das, A. Sivakumar, S. H. Patil and V. V. Andhalkar, Mater. Sci. Eng., C, 2016, 62, 293.

67 A. Bhaskar and V. Nithya, Indian J. Pharmacol., 2012, 44, 694.
68 H. K. Nagar, A. K. Srivastava, R. Srivastava, M. L. Kurmi, H. S. Chandel and M. S. Ranawat, J. Pharm., 2016, 9249040, 8 pages.

69 P. Martin, Science, 1997, 276, 75.

70 S. M. Wahl, N. Mccartneyfrancis and S. E. Mergenhagen, Immunol. Today, 1989, 10, 258.

71 R. B. Mateo, J. S. Reichner and J. E. Albina, Am. J. Physiol., 1994, 266, R1840.

72 K. W. Liechty, N. S. Adzick and T. M. Crombleholme, Cytokine, 2000, 12, 671.

73 V. Pivodova, J. Frankova, A. Galandakova and J. Ulrichova, Nanobiomedicine, 2015, $2,7$.

74 N. Smith, Aust. Dent. J., 1975, 20, 22.

75 S. H. Shin, M. K. Ye, H. S. Kim and H. S. Kang, Int. Immunopharmacol., 2007, 7, 1813. 